\title{
Mercado consumidor de carne suína e derivados em Belo Horizonte
}

[Pork consumer market in Belo Horizonte, Brazil]

\author{
I.G. Faria ${ }^{1}$, J.M. Ferreira ${ }^{2}$, S.K. Garcia ${ }^{2} *$ \\ ${ }^{1}$ Médica veterinária, autônoma \\ ${ }^{2}$ Escola de Veterinária da UFMG \\ Caixa Postal 567 \\ CEP 31270-901 - Belo Horizonte, MG
}

\begin{abstract}
RESUMO
Avaliou-se o comportamento do mercado consumidor de carne suína e seus derivados em Belo Horizonte. Foram entrevistados 401 consumidores, homens e mulheres, maiores de 19 anos de idade, mantendo-se a proporcionalidade observada no censo populacional. Além de sexo e faixa etária, escolaridade, ocupação e renda familiar foram levantadas para compor os fatores condicionantes da pesquisa. A carne suína in natura é consumida até três vezes por semana pela maioria da população (61,6\%), em função de seu sabor e versatilidade. A compra costuma ser feita num mesmo estabelecimento comercial, sendo preferidos os cortes feitos na hora. O consumo de derivados da carne suína é maior que o da carne in natura em razão da grande variedade de produtos. Os consumidores acreditam que a carne suína in natura e derivados sejam perigosos à saúde pelo excesso de gordura ou de colesterol $(38,4 \%)$ e por transmitir doenças $(27,8 \%)$. Sexo, idade e renda familiar têm influência no consumo, mas não escolaridade e ocupação. As marcas dos produtos derivados aumentam a confiabilidade e indicam a origem, para a maioria dos consumidores. A população, embora mais atenta aos conceitos de alimentação saudável e segura, não conhece o significado e a função da rastreabilidade e certificação de origem dos produtos. Para aumentar o consumo e justificar a criação de programa de certificação da carne suína e derivados em Minas Gerais, é necessário campanha dirigida de marketing para eliminar os preconceitos em relação a estes produtos.
\end{abstract}

Palavras-chave: carne suína, comportamento do consumidor

\begin{abstract}
This study aimed to assess the behavior of the consumer in relation to pork and pork products. Four hundred and one consumers, men and women over 19 years old, were randomly sampled from the residents of Belo Horizonte, Minas Gerais, to supply information about pork and pork products consumption, besides school background, occupation and family income. Consumption of fresh pork was directly affected by concepts related to health. The consumers considered pork eating dangerous to health due to an excess of fat, high level of cholesterol and the possibility of diseases transmission. The results suggest that population, even worried about the concepts of healthy and safety feeding, do not know the meaning and the function of the programs of meat quality and origin certification. The importance of the trademarks, which provide reliability and quality of the product, was emphasized. In order to create a program on the certification of pork and pork products in the State of Minas Gerais, it is necessary to run an effective campaign against the pork prejudice
\end{abstract}

Keywords: pork, consumer behavior

Recebido em 4 de março de 2005

Aceito em 19 de dezembro de 2005

*Autor para correspondência (corresponding author)

E-mail: simonekg@vet.ufmg.br 


\section{INTRODUÇÃO}

No mundo todo, cresce a exigência dos consumidores pela segurança alimentar. A certificação internacional é a ferramenta básica para garantir a origem e a qualidade dos produtos e processos agroindustriais e depende de um complexo sistema de informação, ou de rastreabilidade, desde a produção das matériasprimas (Portelle et al., 2000; Cochoy, 2001).

Em uma pesquisa de opinião pública realizada em dez países (Alemanha, Austrália, Brasil, Canadá, China, Índia, Inglaterra, Japão, México e Estados Unidos), 10.000 entrevistados indicaram que a responsabilidade pela segurança dos alimentos seria das companhias produtoras $(36 \%)$, do governo $(30 \%)$, dos próprios consumidores $(15 \%)$, dos agricultores $(6 \%)$, dos varejistas $(5 \%)$ ou de todos estes agentes $(6 \%)$ (Miller, 2001).

Para as indústrias agroalimentares, conhecer as preferências e necessidades do cliente por meio da pesquisa de mercado é um meio de reduzir os riscos de investimento, minimizar erros nos planos de marketing e estabelecer estratégias de gestão.

Embora a carne suína seja a mais consumida em todo o mundo, os consumidores brasileiros dão preferência para as carnes de aves e de bovinos. A média de consumo de carne suína in natura no Brasil é $12,1 \mathrm{~kg} / \mathrm{hab} / \mathrm{ano}$, enquanto a média mundial é $14,5 \mathrm{~kg}$, e a européia é mais de $40 \mathrm{~kg}$ (Abipecs, 2004). Preconceitos e falta de informação sobre a qualidade da carne suína podem ser as causas do baixo consumo.

Em 1994, pesquisa realizada pela Associação Brasileira de Criadores de Suínos (ABCS) com consumidores e representantes da cadeia produtiva em todo o país mostrou que a população brasileira considera 0 sabor 0 principal ponto forte da carne suína ( $92 \%$ das respostas). No entanto, os teores de gordura e a higiene da carne foram considerados pontos fracos por $55 \%$ e $35 \%$ dos entrevistados, respectivamente (Rojo, 1994).

Nos últimos vinte anos, tecnologias de produção e ganhos genéticos na suinocultura reduziram em $31 \%$ a proporção de gordura na carcaça, o que significou $14 \%$ menos calorias e $10 \%$ menos colesterol. No Brasil, Bragagnolo (2001) observou que não há diferença significativa no teor de colesterol entre diferentes cortes, crus e cozidos, de carnes de aves, bovinos e suínos, sendo que o toucinho tem ainda menor concentração de colesterol do que a carne escura e a pele de frango. O INMETRO (2005) divulga resultado semelhante na comparação entre cortes de bovinos e suínos, com ou sem gordura.

Além de atender à preferência do consumidor por carcaças mais magras, houve melhoria na qualidade e na sanidade do rebanho, com controle e erradicação de doenças e redução no uso de medicamentos, e na nutrição e bem-estar dos animais, o que permitiu ao país tornar-se o $4^{\circ}$ maior produtor e exportador mundial de carne suína (Roppa, 2002; Abipecs, 2004).

A região Sudeste do Brasil é um importante centro produtor, abatendo mais de dois milhões de suínos sob Inspeção Federal, em 2004. Minas Gerais é o $4^{\circ}$ produtor e exportador nacional de carne suína (Abipecs, 2004). Em função disso, foi considerado importante definir a demanda da população mineira com relação à carne suína, pois se trata de grande mercado consumidor, com 18.603.198 habitantes, destacando-se a capital, Belo Horizonte, com 2.350.564 habitantes e migrantes de todas as regiões (IBGE, 2005).

Este trabalho teve o objetivo de avaliar o comportamento do mercado consumidor de carne suína e seus derivados em Belo Horizonte, MG.

\section{MATERIAL E MÉTODOS}

Foram realizadas entrevistas domiciliares individuais nas nove regiões administrativas da cidade de Belo Horizonte, MG: Centro-Sul, Noroeste, Nordeste, Leste, Venda Nova, Pampulha, Barreiro, Norte e Oeste. O tamanho e a distribuição da amostragem por região, sexo e faixa etária foram definidos pela Tables for Staticians, de Harkim e Colton (Bernardo Jr., 1995), com base na população de 2.350 .564 habitantes levantada pelo IBGE em 2000, visando ao nível de confiança de $95 \%$. A amostra constou de 401 pessoas maiores de 19 anos que consumiam e/ou compravam carne suína e derivados, das quais $27,9 \%$ tinham entre 20 e 29 anos de idade, $24,4 \%$ entre 30 e 39 anos, $23,9 \%$ entre 40 e 49 anos e $23,7 \%$ tinham 50 anos ou 
mais. 51,6\% eram mulheres. A escolaridade, a renda familiar e a ocupação foram informadas durante a entrevista.

Os questionários foram aplicados em janeiro de 2002 por técnicos treinados do Instituto Leal M Opinião e Mercado e constaram de duas perguntas-filtro, 26 perguntas de conteúdo e cinco perguntas classificatórias, além da identificação do entrevistado. As perguntas e as alternativas de respostas eram lidas, exceto nas questões de opinião, em que primeiro era obtida a resposta espontânea e, depois, feita a leitura das alternativas para a resposta induzida. Para se avaliarem as tendências do mercado da carne suína e o nível de exigência do consumidor, foram formuladas questões sobre a certificação de qualidade e origem.
Os dados primários, obtidos diretamente por meio da aplicação dos questionários, foram tabulados, confrontados segundo os diferentes critérios de classificação da amostra e submetidos à análise estatística descritiva, com ênfase na distribuição de freqüências relativas das respostas (Fonseca e Martins, 1982; Sampaio, 1998).

\section{RESULTADOS E DISCUSSÃO}

$\mathrm{Na}$ Tab. 1, observa-se que $81,3 \%$ dos entrevistados têm até o nível médio de ensino e $60,4 \%$ têm renda familiar de até seis saláriosmínimos (SM). Quanto à ocupação, predominam os profissionais liberais e empregados do comércio ou indústria.

Tabela 1. Distribuição dos critérios de classificação na amostragem dos consumidores de carne suína e seus derivados em Belo Horizonte (MG)

\begin{tabular}{llcc}
\hline Critério & Categoria & $\mathrm{n}$ & $\%$ \\
\hline \multirow{5}{*}{ Escolaridade } & Médio & 170 & 42,4 \\
& Fundamental & 156 & 38,9 \\
& Superior & 73 & 18,2 \\
& Não informou & 2 & 0,5 \\
& Total & 401 & 100 \\
& Até 3 salários-mínimos (SM) & 133 & 33,2 \\
Renda familiar & Entre 3 e 6 SM & 109 & 27,2 \\
& Entre 6 e 10 SM & 73 & 18,2 \\
& Ente 10 e 15 SM & 32 & 8,0 \\
& Mais de 15 & 3,0 \\
& Não informou & 52 & 0,5 \\
& Total & 2 & 100 \\
& Profissional liberal & 401 & 30,7 \\
Ocupação & Empregado do comércio/indústria & 123 & 21,9 \\
& Aposentado & 88 & 12,2 \\
& Dona-de-casa & 49 & 11,7 \\
& Desempregado & 47 & 11,2 \\
& Servidor público & 45 & 7,0 \\
& Estudante & 28 & 3,0 \\
& Empregada doméstica & 12 & 1,7 \\
& Não informou & 7 & 0,5 \\
& Total & 2 & 100 \\
\hline
\end{tabular}

A população de Belo Horizonte consome carne suína in natura com freqüência de uma vez por semana $(28,4 \%)$, duas a três vezes por semana $(26,2 \%)$, uma vez por mês $(26,2 \%)$, quinzenalmente $(11,2 \%)$ ou até diariamente $(7,0 \%)$ (Tab. 2). Homens consomem carne suína até três vezes por semana com maior freqüência $(71,7 \%)$ do que as mulheres $(52,2 \%)$. A maioria das pessoas entre 20 e 29 anos de idade $(59,9 \%)$ consome carne suína de uma a três vezes por semana, enquanto, na faixa de 40 a 49 anos, prevalece o consumo mensal $(34,4 \%)$. Conceitos relativos à boa saúde podem estar relacionados com isso, tais como a quantidade de calorias dos alimentos e o risco de aumento do colesterol. Famílias com renda de até seis SM têm padrão 
semelhante de consumo de carne suína, predominando as freqüências de uma a três vezes por semana e de uma vez por mês, em cerca de $52 \%$ e $27 \%$ das respostas nessas faixas de renda, respectivamente. O consumo de carne suína de uma a três vezes por semana predomina nas famílias com renda de mais de seis a $10 \mathrm{SM}$ $(64,9 \%)$ e com mais de 15 SM $(57,7 \%)$ e é menor na faixa de 10 a 15 SM $(46,9 \%)$, na qual se destaca o consumo mensal $(28,1 \%)$.

Tabela 2. Freqüência de consumo da carne suína in natura e de seus derivados pela população de Belo Horizonte (MG)

\begin{tabular}{lcc}
\hline $\begin{array}{l}\text { Freqüência de } \\
\text { consumo }\end{array}$ & $\begin{array}{c}\text { Carne suína in } \\
\text { natura } \\
\text { (\% das respostas) }\end{array}$ & $\begin{array}{c}\text { Produtos derivados } \\
\text { (\% das respostas) }\end{array}$ \\
\hline $\begin{array}{l}\text { Uma vez por } \\
\text { semana }\end{array}$ & 28,4 & 24,2 \\
$\begin{array}{l}\text { Duas a três } \\
\text { vezes por }\end{array}$ & 26,2 & \\
semana & 26,2 & 29,2 \\
Mensalmente & 11,2 & 13,0 \\
Quinzenalmente & 7,0 & 6,7 \\
Diariamente & - & 17,0 \\
Nunca & 1,0 & 10,0 \\
Não respondeu & & - \\
\hline
\end{tabular}

Confirmando a pesquisa realizada pela $\mathrm{ABCS}$ (Rojo, 1994), o sabor é o principal motivo para o consumo da carne suína in natura para $65,9 \%$ dos consumidores, tanto nas respostas espontâneas quanto nas induzidas, seguido pelo motivo de "variar o cardápio" (27,7\%). Também são citadas a praticidade ou versatilidade da carne suína, tradição e maciez. O preço foi um motivo pouco mencionado pelos consumidores $(13,7 \%)$

As principais preocupações dos consumidores são o teor de gordura ou colesterol $(38,4 \%)$, o perigo para a saúde no aspecto sanitário $(27,8 \%)$ e o excesso de calorias (13\%), indicando que a população não está suficientemente esclarecida sobre composição, valor nutricional e qualidade da carne suína produzida atualmente, conforme constataram Rojo (1994) e Tramontini (2000) no Brasil.

Alguns fatores decisivos no momento da aquisição da carne suína in natura são aparência $(44,4 \%)$, sabor $(28,2 \%)$, preço $(13,7 \%)$ e frescor do produto $(12,5 \%)$.
A carne cortada no momento da compra é preferida por $77,8 \%$ dos consumidores, seguido pela embalagem em bandeja (14\%) e a vácuo $(7,5 \%)$.

Outros fatores, como fidelidade ou confiança no estabelecimento comercial, qualidade, conveniência e preço determinam o hábito de compra, conforme demonstrado na Tab. 3.

Tabela 3. Hábitos de compra da carne suína in natura pelos consumidores de Belo Horizonte (MG)

\begin{tabular}{lc}
\hline Hábitos de compra & $\%$ \\
\hline Compra sempre no mesmo lugar & 45,9 \\
Procura por produto de qualidade & 20,7 \\
Compra onde for mais conveniente & 13,2 \\
Procura o melhor preço & 12,5 \\
Procura variar o estabelecimento & 7,7 \\
\hline
\end{tabular}

Eleger um mesmo local para a compra pode estar associado a diversos fatores, tais como um vínculo de confiança estabelecido entre cliente e vendedor, seja por fatores inerentes ao produto ou relativos ao próprio consumidor, ou ter à disposição diversos produtos em um mesmo local, no caso de supermercados e butiques de carne, com grande variedade de cortes, tipos e embalagens, ou, ainda, pela proximidade da residência, especialmente açougues de pequeno e médio portes.

No mercado nacional, há uma ampla variedade de produtos derivados da carne suína, tais como os embutidos, salgados, defumados, pré-cozidos e semi-prontos, com qualidade, marcas e preços diferenciados, visando atingir consumidores de todas as classes sócioeconômicas. Por isso, é provável que o consumidor tenha sempre algum derivado da carne suína à mesa.

De fato, a maioria da população de Belo Horizonte consome derivados da carne suína semanalmente, seja duas a três vezes $(29,2 \%)$, uma vez (24,2\%) ou diariamente (17\%) (Tab. 2). $\mathrm{O}$ maior consumo dos derivados em relação à carne suína in natura pode ser devido à maior diversificação e praticidade em seu preparo. Cerca de $30 \%$ das pessoas entre 20 e 39 anos de idade consomem derivados diariamente, enquanto que aproximadamente $28 \%$ das pessoas entre 40 e 59 anos o fazem uma vez por mês, demonstrando que a idade influencia a freqüência do consumo de derivados, assim 
como o de carne suína in natura. A renda familiar influencia o consumo de derivados da mesma forma, sendo que o consumo mensal é mais citado na faixa de renda de até três SM. No estudo de Poletto et al. (2001), o comportamento de compra de derivados da carne suína nas capitais de São Paulo e do Sul é determinado pelas mulheres, com mais de 30 anos e renda de seis a dez SM. Apenas 10\% não consomem derivados de carne suína.

Para os consumidores, os dois principais aspectos positivos com relação aos derivados de carne suína são o sabor $(33,8 \%)$ e a facilidade de preparo $(15,8 \%)$. Os aspectos negativos são o teor de gordura $(21,9 \%)$, risco à saúde $(13,3 \%)$ e excesso de calorias $(11,1 \%)$, da mesma forma que a opinião sobre a carne in natura, acrescentando, ainda, a presença de conservantes, perda do sabor natural, marcas ruins, excesso ou tipo de tempero, dureza da pele do bacon, curto período de validade, baixo rendimento e cheiro ruim. $\mathrm{O}$ preço foi citado por apenas 3,6\% dos entrevistados.

Observa-se que o conceito que o consumidor tem da carne suína se estende aos derivados, influenciando igualmente seu consumo. Isso demonstra a importância do trabalho de marketing na eliminação de preconceitos e modificação da imagem da carne suína. De fato, $35,4 \%$ dos consumidores preferem a carne de aves e $35,4 \%$ a de bovinos, enquanto $26,7 \%$ preferem a carne suína. A carne de aves é considerada a mais saudável por $70,8 \%$ da população, especialmente pelas mulheres $(59,2 \%)$, seguido pela carne de bovinos (19\%) e de suínos $(6,2 \%)$. Em vários países, constatou-se que a carne de aves é tida como mais magra, preferida por pessoas em dieta de baixas calorias, além de ser recomendada por médicos e nutricionistas para evitar o excesso de colesterol na dieta (Issanchou, 1996; Machado Filho, 2000). A renda familiar, no entanto, determina esta preferência, sendo que a carne suína é preferida pela população na faixa de até três SM.

A percepção do consumidor sobre a qualidade de um produto baseia-se em suas características físicas e nas informações sobre ele. O carimbo do Serviço de Inspeção Federal é uma garantia de qualidade para os produtos de origem animal, já que informa o consumidor que aquele produto é seguro para o consumo. 57,1\% dos consumidores sabem o que é carne inspecionada, mas $42,9 \%$ desconhecem o assunto. Destes, $62,2 \%$ possuem apenas o ensino fundamental e $50 \%$ possuem renda familiar de até três SM, contra apenas 3,5\% dos consumidores com mais de 15 SM. Portanto, a classe sócio-econômica interfere no nível de conhecimento e exigência do consumidor.

No momento da compra, a maioria dos consumidores $(71,6 \%)$ não procura saber a origem do produto que está adquirindo e $27,2 \%$ verificam esta informação. A rastreabilidade é a principal ferramenta utilizada na certificação de origem dos produtos cárneos, mas $82,8 \%$ dos consumidores desconhecem seu significado. Resultado semelhante $(72,1 \%)$ foi encontrado quanto à certificação de origem.

Embora o programa de certificação de origem tenha sido aprovado pelo Governo Federal e existam prazos para implantação da rastreabilidade no setor de carnes, principalmente a bovina, visando atender ao mercado externo e aumentar o nível de segurança alimentar, os consumidores não estão informados sobre a importância destes programas, ao contrário dos consumidores europeus, americanos e canadenses, para os quais os conceitos de qualidade e segurança alimentar são relacionados com a certificação de produtos (Issanchou, 1996; Verbeke et al., 1999).

Para Verbeke (2000), a mídia pode influenciar negativamente ou positivamente na imagem do produto e na decisão de compra. As marcas beneficiam a sociedade, pois melhoram e padronizam a qualidade e inovam os produtos, visando à diferenciação dos concorrentes, que é uma das principais questões na estratégia de marketing de produtos.

No mercado consumidor de Belo Horizonte, MG, a importância da marca comercial dos produtos derivados da carne suína deve-se ao elo de confiança com o fabricante $(37,9 \%)$ e ao fato de indicar a origem $(29,7 \%)$ e manter um padrão do produto (10,7\%). Para 55,9\% dos consumidores, a escolha por determinada marca está associada à qualidade do produto, à propaganda $(14 \%)$ ou ao preço $(9,2 \%)$. Para $9 \%$ da população, a marca não é importante. 
Como não existem no Brasil marcas consolidadas para a carne suína in natura, o principal critério de escolha do consumidor é a aparência do produto, como foi constatado neste trabalho. Entretanto, no caso dos derivados, a qualidade do produto para os consumidores está relacionada à marca comercial. A embalagem é um importante fator de caracterização visual da qualidade do produto. Nos rótulos, os consumidores observam as datas de fabricação $(34,2 \%)$ e validade $(24,7 \%)$, o selo de garantia de origem $(12,7 \%)$ e as informações nutricionais (7\%). Com menor freqüência (menos de 4\%), todas as informações exigidas por lei foram lembradas pelos consumidores.

\section{CONCLUSÕES}

Apesar dos avanços tecnológicos em sua produção, conceitos ultrapassados influenciam negativamente a imagem do consumidor sobre a carne suína e seus derivados, que são considerados ricos em gordura, com elevado teor de colesterol e potencialmente perigosos à saúde. A mudança dessa imagem requer investimentos em marketing, já que o preço dos produtos não é fator limitante para o consumo. A população deve ser informada sobre a importância dos programas de certificação de origem e qualidade, pois, embora a qualidade dos produtos determine a opção por eles, ainda não existe demanda efetiva pela certificação.

\section{AGRADECIMENTOS}

À Associação dos Suinocultores do Estado de Minas Gerais (ASEMG) e ao Instituto Mineiro de Agropecuária (IMA).

\section{REFERÊNCIAS BIBLIOGRÁFICAS}

ABIPECS. Associação Brasileira da Indústria Produtora e Exportadora de Carne Suína. Relatório Anual 2004. Disponível em <www.abipecs.com.br>. Acessado em 15.05.2005.

BERNARDO JÚNIOR., F. A pesquisa: o que é para que serve. Brasília: Sebrae, 1995. v.1, 66p. (Série Marketing para a Pequena Empresa, n.6).

BRAGAGNOLO, N. Aspectos comparativos entre as carnes segundo a composição de ácidos graxos e teor de colesterol.
In: CONFERÊNCIA INTERNACIONAL VIRTUAL SOBRE QUALIDADE DA CARNE SUÍNA, 2., 2001. Disponível em <www.conferencia.uncnet.br>. Acessado em 12.05.2005.

COCHOY, F. Les effets d'un trop plein de traciabilité. Recherche, n.339, p. 66-68, 2001.

FONSECA, J.S.; MARTINS, G.A. Curso de estatística. 3 ed. São Paulo:Atlas, 1982. 286 p.

IBGE. Instituto Brasileiro de Geografia e Estatística. Banco de dados agregados. Disponível em: <http://www.sidra.ibge. gov.br>. Acessado em 17.08.2005

INMETRO. Teor de gordura e colesterol nas carnes de bovinos e suínos. Disponível em <www.inmetro.gov. $\mathrm{br} /$ consumidor/produtos/teorGordura.asp $>$. Acessado em $30 / 06 / 2005$

ISSANCHOU, S. Consumer expectations and perceptions of meat and meat product quality. Meat Sci., v.43, p.5-19, 1996.

MACHADO FILHO, L.C.P. Bem-estar de suínos e qualidade de carne: uma visão brasileira. In: CONFERÊNCIA INTERNACIONAL VIRTUAL SOBRE QUALIDADE DA CARNE SUÍNA, 1., 2000. Disponível em: $<$ http://www.conferencia.uncnet.br/pork $>$. Acessado em 30.11.2000.

MILLER, D. Global consumers trends. CIES Food Business Forum. In: INTERNATIONAL FOOD SAFETY CONFERENCE, Geneva, 2001.

POLETTO, A.R.; SANTOS FILHO, I.J.; BARNI, E.J. Avaliação do potencial de mercado dos produtos industrializados derivados de suínos. In: CONFERÊNCIA INTERNACIONAL VIRTUAL SOBRE QUALIDADE DA CARNE SUÍNA, 2., 2001. Concórdia: Embrapa, 2001. 29p. (Via Internet)

PORTELLE, D.; HAEZEBROECK, V.; RENAVILLE, R. et al. Meat channel traceability. Biotech. Agron. Soc. Environ., v.4, p.233-240, 2000.

ROJO, F. Sumário do estudo sobre o mercado de produtos derivados de suínos. Estrela:Francisco Rojo Consultoria de Marketing, 1994. 13p. (Relatório apresentado à ABCSSINASUI).

ROPPA, L. Carne suina: mitos e verdades. Disponível em: $<$ http://www.porkworld.com.br>. Acesso em 30.04.2002.

SAMPAIO, I.B.M. Estatística aplicada à experimentação animal. Belo Horizonte: FEPMVZ, 1998. 221p.

TRAMONTINI, P. Consumo da carne suína: a experiência brasileira. In: SEMINÁRIO INTERNACIONAL DE SUINOCUlTURA, 5., São Paulo, 2000. Anais... São Paulo, 2000. p.6-11.

VERBEKE, W. Influences on the consumer decision making process towards fresh meat: insights from Belgium and implications. Br. Food J., v.2, p.522-538, 2000.

VERBEKE, W.; DECKEL, M.J.; WARNANTS, N. et al. Consumer perception: facts and possibilities to improve acceptability of health and sensory characteristics of pork. Meat Sci., n.53, p.77-99, 1999. 